\title{
PRINCIPAL COMPONENT AND CLUSTER ANALYSES ON TANZANIA OIL PALM Elaeis guineensis JACQ. GERMPLASM
}

\author{
SUZANA, M*; ZULKIFLI, $Y^{*}$; MARHALIL, $M^{*}$; RAJANAIDU, ${ }^{*}$ and MEILINA ONG-ABDULLAH*
}

\begin{abstract}
Genetic variability in germplasm collection is explored for its role in improving plant breeding strategies. In this study, we assessed the pattern of variation on 15 yield and bunch components in 2191 Elaeis guineensis dura germplasm from 13 populations (TZA01-TZA13) originating from Tanzania and planted in Malaysia in 1990. The data retrieved from the Malaysian Palm Oil Board-Breeding Information System (MPOB-BIS) were standardised prior to principal component analyses (PCA) and cluster analyses (CA) using SAS 9.4. First four principal component (PC) (PC1-PC4) having eigenvalue $>1$ accounted for $92.33 \%$ of the total variability with values $41.94 \%, 25.09 \%, 16.35 \%$ and $8.95 \%$, respectively. PC1 has largest positive association with oil to dry mesocarp, oil to bunch and oil to wet mesocarp whereas largest negative association with kernel to fruit, kernel yield and kernel to bunch. PC2 is positively associated with mean fresh fruit bunch, mean average bunch weight, oil and kernel yield whereas negatively associated with shell to fruit and fruit to bunch. CA revealed high genetic variability lies within Tanzania germplasm collection. The combination of PCA and CA is a useful tool to select specific populations to establish core collection for better efficiency in oil palm improvement.
\end{abstract}

Keywords: oil palm germplasm, multivariate analysis, eigenvalue.

Date received: 9 July 2018; Sent for revision: 9 July 2018; Accepted: 20 January 2019.

\section{INTRODUCTION}

Oil palm, Elaeis guineensis Jacq., a palm of African origin produces palm oil, which has historically been used as a staple food source dating as far back as 5000 years, accounting for $30.8 \%$ of today's global production of oils and fat (Mielke, 2018). Its versatility makes it a sought-after ingredient in food and non-food industry. Vast oil palm plantations have been established in tropical countries such as Malaysia and Indonesia due to favourable climatic conditions. In 2017, these two countries produced close to one-third (75.17 million tonnes) of world's

\footnotetext{
Malaysian Palm Oil Board,

6 Persiaran Institusi, Bandar Baru Bangi,

43000 Kajang, Selangor, Malaysia.

E-mail: suzana.mustaffa@mpob.gov.my
}

total oils and fat production from a planted area of 19.04 million hectares (Kushairi et al., 2018). Malaysia is the world's second largest producer and exporter of palm oil after Indonesia, with a 29\% market share of an annual export market worth USD 9.7 billion in 2017 (Workman, 2018). Agricultural products including palm oil need to increase by $70 \%$ and net exports of oilseeds and vegetable oils are predicted to triple by 2050 to fulfil market demand as the population growth touching 9 billion (Kushairi et al., 2017).

The introduction of Deli dura seeds from four Bogor palms from Indonesia to Malaya (now known as Malaysia) in 1911 and 1912 (Jagoe, 1952) marked the beginning of the Malaysian oil palm industry. Planting materials of dura fruit form was planted then until planting materials of tenera fruit form with higher oil content was discovered, 
and the monogenic inheritance that governs the variation in fruit forms was reported by Beirnaert and Vanderweyen (1941). This discovery had led to further growth of the oil palm industry worldwide. In order to realise the potential of this industry, planting materials of tenera/pisifera fruit forms of AVROS lineage were brought into Malaya in 1957 (Kushairi, 2009). Strategies such as this which are imbibed as part of our breeding improvement programmes have helped and placed Malaysia as the world's leading producer and exporter of palm oil in the 1960s (Ooi et al., 2014). However, the genetic base was still considered narrow at that time, thus limiting potential enhancement of fresh fruit bunch (FFB) yield and its components, e.g. bunch number and bunch weight (Okwuagwu, 1995). In production of planting materials of tenera fruit form, which commonly involves crossing between dura and pisifera (DxP), Marhalil (2009) reported that improvement for dura mother palms is required to increase oil palm yield and quality of the commercial DxP planting materials, as the recurrent utilisation of Delis in many breeding programmes without other origins, might inhibit genetic improvement of bunch yield. To address this problem, one of the efforts undertaken was to broaden the gene pool by collecting $E$. guineensis germplasm materials from its natural habitat in Africa. In 1973 and 2010, the Malaysian Palm Oil Board (MPOB), previously known as the Palm Oil Research Institute of Malaysia (PORIM), led the bioprospection activities to 11 African countries and today the collection formed the largest ex situ oil palm conservation programme in the world (Rajanaidu, 1994; Rajanaidu and Jalani, 1994).

In oil palm, agronomic and morphological aspects can directly or indirectly influence oil production. Thus, understanding the genetic variability found amongst the wild oil palm collections is essential to identify and select superior palm before it is being utilised in crossbreeding programme with existing advanced populations. Evgenidis et al. (2011) claimed that the assessment of germplasm is the most crucial and should be prioritised. This knowledge can be established through assessment on pedigree, morphology, biochemistry, agronomic performance and molecular level (Mohammadi and Prasanna, 2003). Genetic diversity based on morphological variables of many crops have been successfully evaluated using both principal component analysis (PCA) and cluster analysis (CA). For example, PCA and CA have revealed diversity pattern in tomato (Evgenidis et al., 2011), wheat (Khodadadi et al., 2011; Beheshtizadeh et al., 2013), rice (Maji and Shaibu, 2012), ginger (Ravishanker et al., 2013), white bean (Koij and Saba, 2015) and sugar beet (Danojević et al., 2016). However, application of PCA and CA based on field evaluation in characterising oil palm is still considered limited (Li-Hammed et al., 2016), with the only known published studies conducted by Ekezie (2013), Camillo et al. (2014), Suzana et al. (2016) and Li-Hammed et al. $(2015 ; 2016)$.

Tanzania is located on the eastern part of Africa. Due to its favourable tropical climate, oil palm grows naturally and its products are traditionally used for food, as building materials and for medicinal purposes (Carrere, 2013). MPOB, in collaboration with the Ministry of Agriculture in Tanzania, has successfully collected germplasm in 1986. In Tanzania, open pollinated bunches were collected from one to seven palms from each collection site, with a total of 13 sites, located near Kigoma along the Lake Tanganyika (Rajanaidu et al., 1992). A total of 42 dura bunches were collected with full record of their characteristics: mean bunch weight was $18.4 \mathrm{~kg}$, mean fruit weight was $16.9 \mathrm{~g}$, mean nut weight was $8.9 \mathrm{~g}$, mesocarp to fruit was $46.7 \%$, fruit diameter was $2.7 \mathrm{~cm}$, nut diameter was $2.0 \mathrm{~cm}$ and kernel diameter was $1.3 \mathrm{~cm}$ (Rajanaidu et al., 1992; 2017). Further evaluation on this dura collection revealed the potentiality of having individual palms with high bunch index (BI: $>0.6)$, high vitamin $\mathrm{E}$ (>1300 ppm), high carotene (>2000 ppm), low lipase (free fatty acids: $2 \%-10 \%$ ) and high protein kernel $(>20 \%)$. Materials involved has been released to the industry through several MPOB-PORIM Series as PS7 (Junaidah et al., 2004), PS8 (Kushairi et al., 2004), PS11 (Mohd Din et al., 2006), PS13 (Maizura et al., 2008) and PS14 (Noh et al., 2015). Some dura materials also showed compact characteristics with height increment $<0.30 \mathrm{~m} \mathrm{yr}^{-1}$ and rachis length $<5.0 \mathrm{~m}$ (Marhalil, 2009). In order to optimally exploit these interesting traits, understanding the genetic diversity is crucial to enable selection of the best parents for development of new breeding materials.

\section{MATERIALS AND METHODS}

A total of 2283 dura palms derived from open pollinated bunches, with the range of 15 to 61 palms per open pollinated bunch were planted at Bukit Lawiang in MPOB Research Station Kluang, Johor, Malaysia in 1990. Palms were laid out in four replicates using randomised complete block design (RCBD) with 16 palms plot $^{-1}$ replicate $^{-1}$ in a triangular form, with a distance at $9 \mathrm{~m}$ apart, giving 148 palms $\mathrm{ha}^{-1}$. This experiment was labelled as Trial 0.256 and each population was indicated as TZA01-13 according to the original collection sites in Tanzania, with the range of one to six families per population. Yield data collection (YR) and bunch analysis (BA) on individual palms were carried out from 1994 until 2000. Bunch quality characters were evaluated using protocol developed by Blaak et al. (1963). All data were systematically uploaded into MPOB-Breeding Information System (MPOB-BIS). 
Three components for bunch yield and its components were used: fresh fruit bunch (FFB), bunch number (BNO) and average bunch weight (ABW). Meanwhile, the 12 components for bunch quality were: mean fruit weight (MFW), mean nut weight (MNW), mesocarp to fruit (MTF), kernel to fruit (KTF), shell to fruit (STF), oil to dry mesocarp (OTDM), oil to wet mesocarp (OTWM), fruit to bunch (FTB), oil to bunch (OTB), kernel to bunch (KTB), oil yield (OY) and kernel yield (KY).

Total number of dura palms analysed were 2191 after removing abnormal, supply and dead palms. Population mean for each component, trial mean and standard deviation were obtained using SAS software ver 9.4. Data was then analysed for PCA after being standardised (mean $=0$, standard deviation $=1$ ). Standardisation is needed prior to actual analysis to ensure data normality, change the weight of different variables and remove the effect of measurement units (Cao et al., 1999). In PCA, the correlation matrix between all components was calculated with the respective eigenvalues and scores were plotted with respect to PC1 and PC2. Ward's Minimum Variance based on Euclidean distance was used to construct a phylogenetic relationship in CA using NCSS Statistical Software ver 11.0.12.

\section{RESULTS AND DISCUSSION}

\section{Mean Performance of Yield and Bunch Quality Traits}

Table 1 shows the mean performance of 13 populations for Tanzania dura in Trial 0.256 for yield and bunch quality traits. The grand mean performance for FFB yield was $121.05 \mathrm{~kg} \mathrm{palm}^{-1} \mathrm{yr}^{-1}$, with mean BNO of 13.08 bunches palm ${ }^{-1} \mathrm{yr}^{-1}$ and $\mathrm{ABW}$ of $9.39 \mathrm{~kg} \mathrm{palm}^{-1} \mathrm{yr}^{-1}$. Population TZA04 produced the highest mean FFB of all populations $(139.15 \mathrm{~kg}$ palm ${ }^{-1} \mathrm{yr}^{-1}$ ) which was about $14.95 \%$ higher than the grand mean FFB of this trial and also 9.09\% higher than DxP standard cross (SC) (127.56 kg palm $\left.{ }^{-1} \mathrm{yr}^{-1}\right)$. The result obtained by TZA04 was attributed to high BNO of $14.41 \mathrm{~kg}$ palm ${ }^{-1} \mathrm{yr}^{-1}$ and balanced ABW (9.76 $\mathrm{kg}$ palm $\left.\mathrm{yr}^{-1}\right)$. Tanzania dura populations tend to have higher $\mathrm{BNO}$ and lower $\mathrm{ABW}$, a character which was similar to MPOB Nigerian material reported by Isa et al. (2008). Population TZA10 obtained the highest ABW (10.37 kg palm $\left.{ }^{-1} \mathrm{yr}^{-1}\right)$ but was still low compared to DxP (14.21 kg palm $\left.{ }^{-1} \mathrm{yr}^{-1}\right)$.

Mean value for MFW which comprises dura mesocarp, shell and kernel in this trial was $9.64 \mathrm{~g}$, comparable to the DxP SC $(9.30 \mathrm{~g})$. The highest MFW $(10.40 \mathrm{~g}), \mathrm{MNW}(5.23 \mathrm{~g})$ and MTF (49.69\%) were all from TZA13. Mean values of other traits such as $\operatorname{KTF}(13.37 \%)$, STF $(38.99 \%)$, OTDM $(76.54 \%)$, FTB $(63.39 \%)$, OTB $(13.92 \%)$ and KTB $(8.44 \%)$ are considered satisfactory for dura standard as compared to previous analysis on Tanzania dura germplasm based on family (Marhalil, 2009) and Nigerian dura x Deli dura introgression (Noh et al., 2014). In terms of OY, mean value of Tanzania dura materials (16.74 $\left.\mathrm{kg} \mathrm{palm}^{-1} \mathrm{yr}^{-1}\right)$ was still very low compared to DxP SC $\left(28.25 \mathrm{~kg} \mathrm{palm}^{-1} \mathrm{yr}^{-1}\right)$, considering its high KY (10.20 kg palm $\left.\mathrm{yr}^{-1}\right)$.

\section{Correlation Analysis}

Correlation analysis for 15 traits studied is shown in Table 2. For bunch yield characters, FFB is positively correlated to BNO $(r=0.622)$ and ABW (0.442), but BNO is negatively correlated to ABW $(\mathrm{r}=-0.419)$. According to previous studies, it is proven that $\mathrm{FFB}$ is positively correlated to $\mathrm{BNO}$ and $\mathrm{ABW}$. However, $\mathrm{BNO}$ and $\mathrm{ABW}$ are negatively correlated, thus showing an antagonistic effect of the two yield component traits in the performance of oil palms (Marhalil et al., 2009; Djonko et al., 2011). In terms of bunch quality components, the highest significant and positive correlation was observed between OTDM - OTWM (0.987), OTB - OTWM (0.955) and MNW - MFW (0.946). OY was positively correlated with all the other traits except STF. The highest negative correlation was obtained between STF - MTF (-0.898) and all other negative correlations showed either moderate $(<-0.700)$ or low $(<0.300)$ correlation.

\section{Principal Component Analysis (PCA)}

Dimension-reduction method of PCA is beneficial in exploring the traits contributing most to variation, thus directly assist the process of plant breeding. PCA studies showed that the first four principal component (PC) have eigenvalue $>1.0$ which accounted for $92.33 \%$ of the total variability reliable (Figure 1). Eigenvalues $>1.0$ has been suggested to be the rule of thumb of how many useful PC having any practical significance and should be retained (Iezonni and Pritts, 1991). The remaining components therefore could be neglected as being not of much significance. A similar study by Li-Hammed et al. (2016) also reported six PC having eigenvalue $>1$, but contributed to the lower total variation $(85.52 \%)$ among the MPOB-Nigerian oil palm germplasm based on yield and yield components traits.

In this study, PC1 has the eigenvalue of 6.291, which represents $41.94 \%$ of the total variation in the data set whereas PC2 and PC3 have eigenvalues of 3.764 and 2.452, respectively with additional variation at $25.09 \%$ and $16.35 \%$ (Table 3). This suggests that PC1, PC2 and PC3 represent the equivalent of six, four and two individual variables respectively. Thus, the genotypes from this PC1 to PC3 will be significant and should be selected for further evaluation in selective breeding programme. 


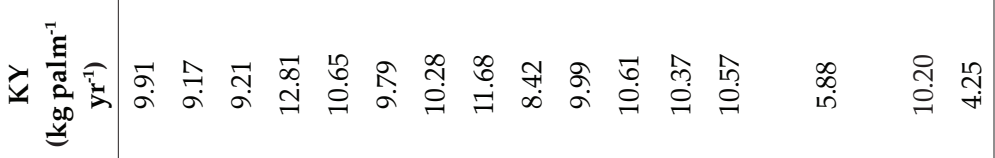

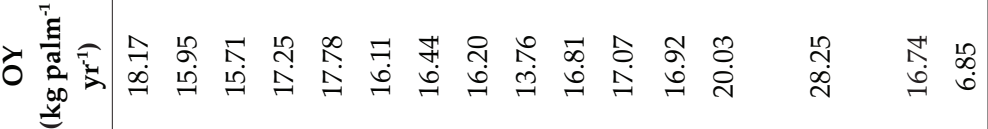
包 苛 ڤ ब

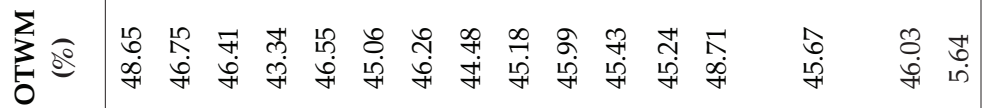

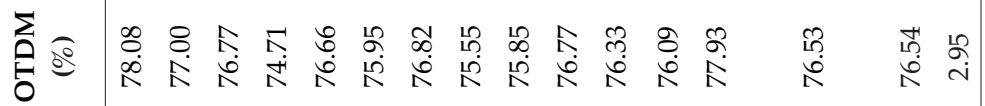

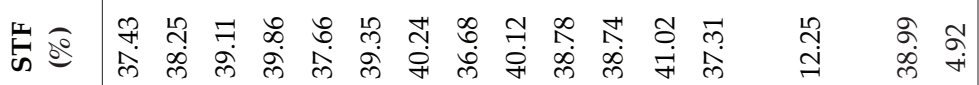
岂

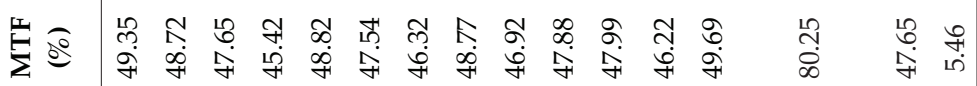

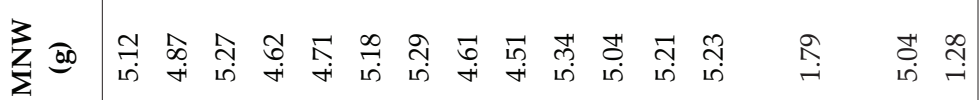

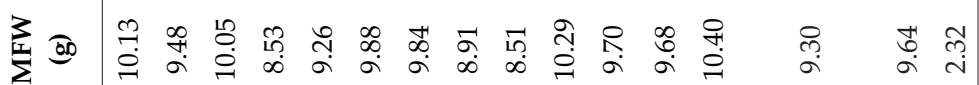

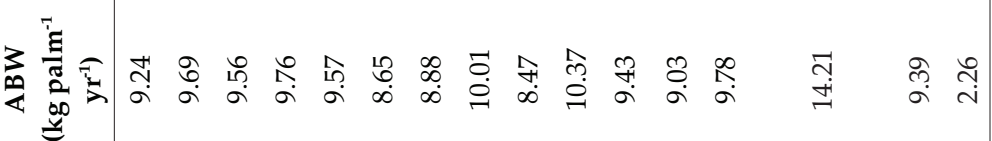

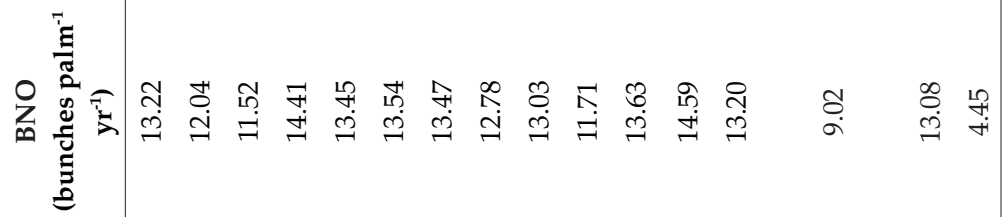

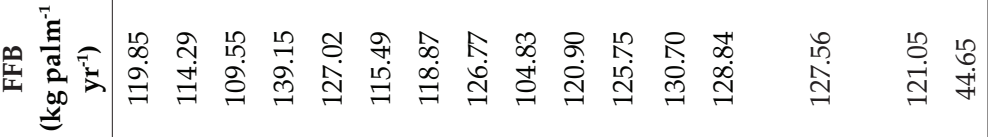

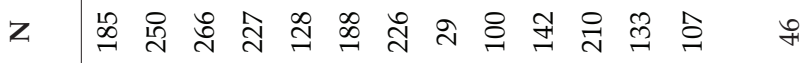

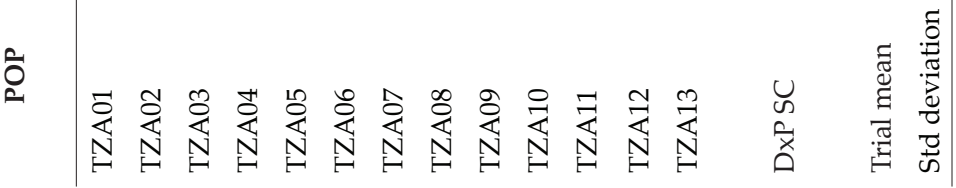

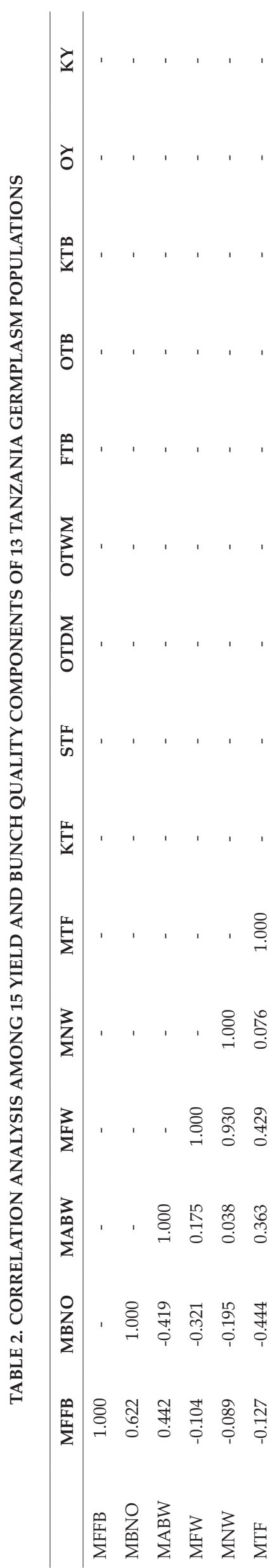




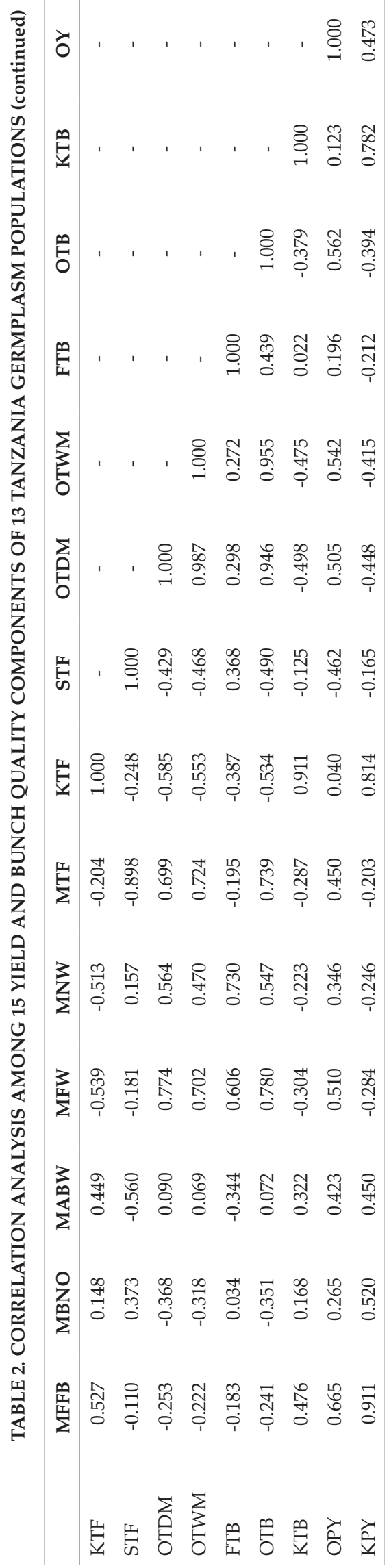

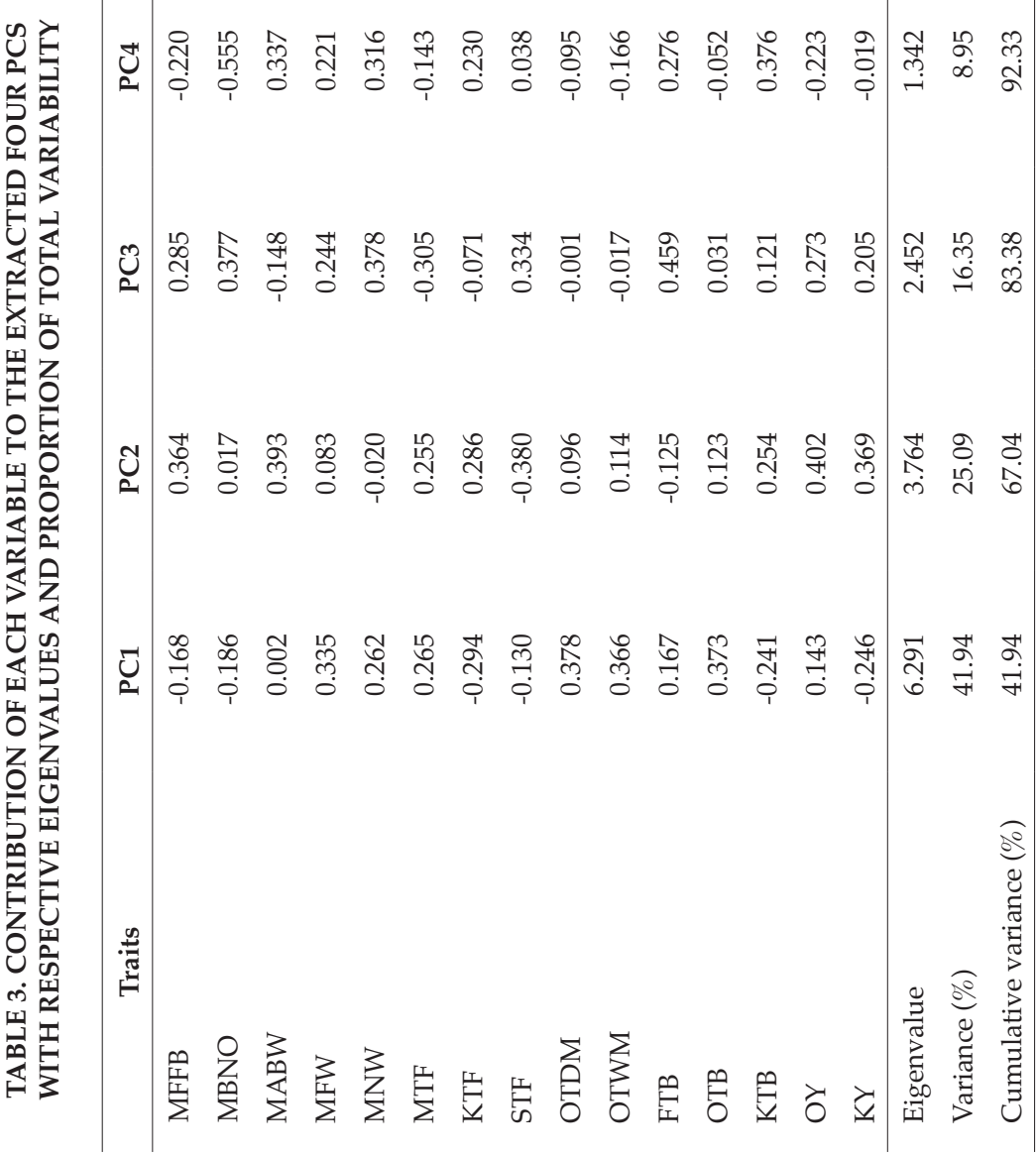


PC4 had eigenvalue of 1.342 with corresponding variance percentage of $8.95 \%$ which symbolises of only one equivalent variable. Thus, this PC should be considered significant if only it has some biological meaning.

All associations were either low to moderate for both positive and negative contributions with no associations observed above 0.600 . PC1 has the highest positive and moderate association with OTDM (0.378), OTB (0.373), OTWM (0.366) and MFW (0.335). Low association on PC1 was observed for MTF (0.265), MNW (0.262), FTB (0.167), OY (0.143) and $A B W$ (0.002). Meanwhile, it was negatively associated with KTF (-0.294), KY (-0.246) and KTB (-0.241). PC2 was positively associated with OY (0.402), KY (0.369), ABW (0.393) and FFB (0.364), whereas negatively associated with STF $(-0.380)$ and FTB (-0.125). PC3 was positively associated with FTB (0.459), MNW (0.378), BNO (0.377) and STF (0.334), whereas negatively associated with MTF (-0.305) and $\mathrm{ABW}(-0.148)$.

PC1 to PC3 were plotted to observe the relationship among the 13 populations of Tanzanian germplasm (Figure 2). TZA13 and TZA01 were positioned at the top right-hand corner of the score plot and showed the most positive along PC1. These might due to high bunch quality performance obtained by both populations such as highest MTF (49.69\% and 49.35\%), OTDM (77.93\% and $78.08 \%)$, OTWM $(48.71 \%$ and $48.65 \%)$, OTB $(15.59 \%$ and $15.17 \%)$ and OY $\left(20.03 \mathrm{~kg} \mathrm{palm}^{-1} \mathrm{yr}^{-1}\right.$ and $\left.18.17 \mathrm{~kg} \mathrm{palm} \mathrm{yr}^{-1}\right)$, respectively. STF ratio for

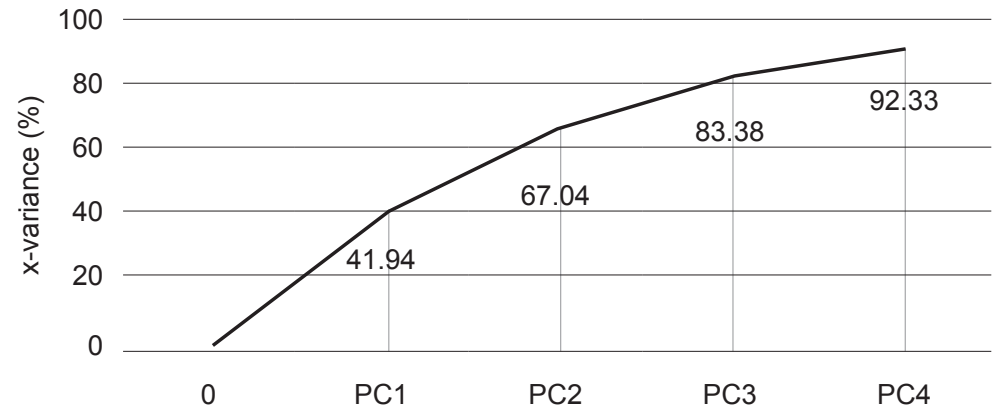

Figure 1. Variance accumulated curve.
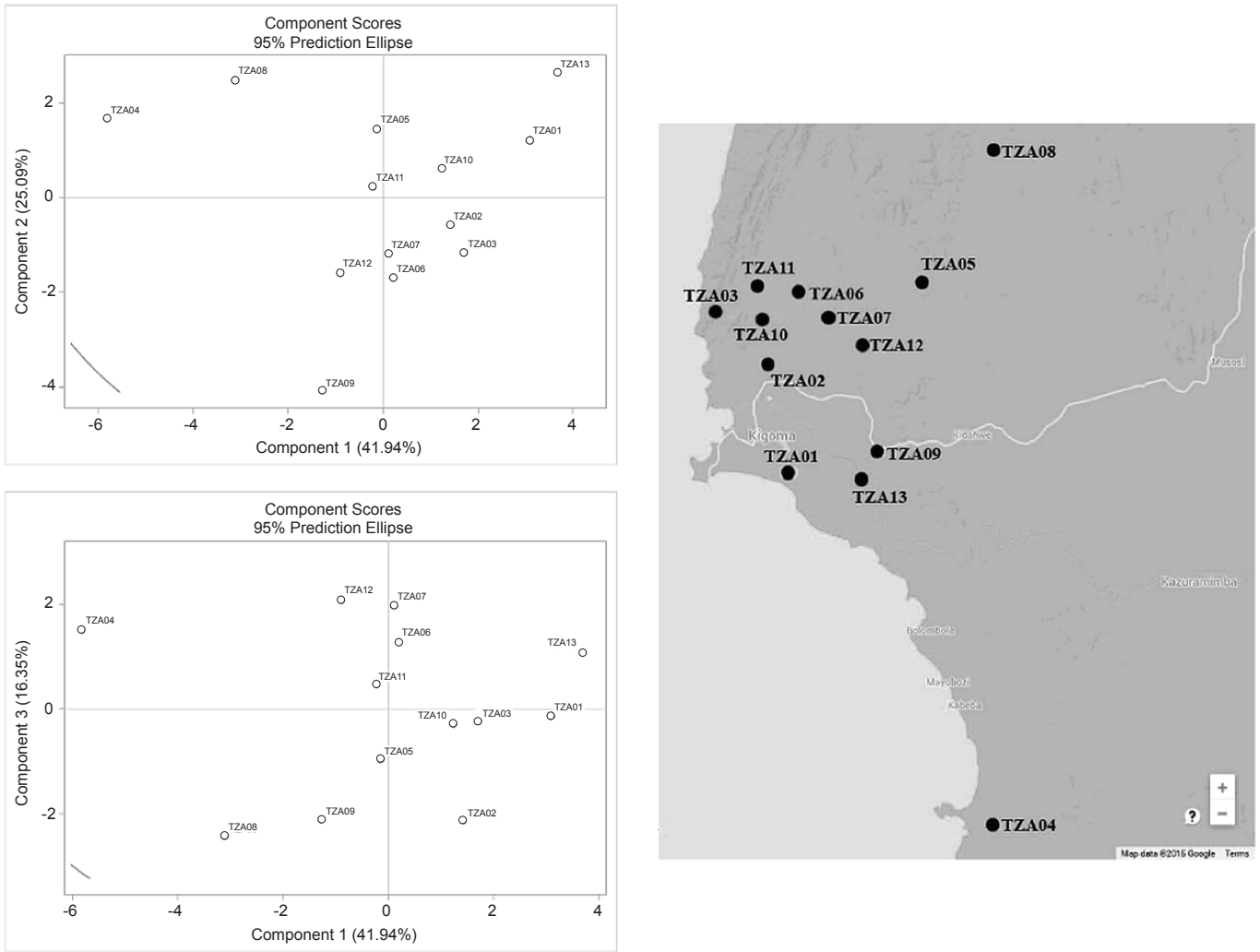

Figure 2. Principal component analyses (PCA) scores extracted from PC1, PC2 and PC3 based on 95\% Prediction Ellipse and comparison to the original locations of TZA populations collected in Tanzania. 
both populations were also among the lowest $(37.43 \%$ and $37.31 \%)$ and they performed well in yield and its components with their corresponding FFB (128.84 and $\left.119.85 \mathrm{~kg} \mathrm{palm}^{-1} \mathrm{yr}^{-1}\right)$, BNO (13.20 and 13.22 bunches palm ${ }^{-1} \mathrm{yr}^{-1}$ ) and ABW (9.78 and $\left.9.24 \mathrm{~kg} \mathrm{palm}^{-1} \mathrm{yr}^{-1}\right)$ were among the highest compared to the rests. TZA13 was also the most positive in PC2 due to the highest OY $(20.03 \mathrm{~kg}$ palm $\left.^{-1} \mathrm{yr}^{-1}\right)$ and lowest STF $(37.31 \%)$. The highest ABW was observed in TZA10 $\left(10.37 \mathrm{~kg}\right.$ palm $^{-1}$ $\left.\mathrm{yr}^{-1}\right)$ but it failed to give the highest FFB due to low BNO (11.71 bunches $\mathrm{yr}^{-1}$ ). High BNO is the easiest way to get high FFB. Nevertheless, the increase in $\mathrm{ABW}$ is associated with the reduction in BNO. Thus, when $\mathrm{BNO}$ is maximised (i.e., one bunch per leaf), ABW contributes to the difference in the total FFB production. This might due to negative correlation of $\mathrm{BNO}$ and $\mathrm{ABW}$ which causes great difficulties to maximise both variables in the same palm in order to get higher yield. However, high selection pressure over a long period of time may resolve this obstacle (Kushairi et al., 2003).

TZA04 and TZA08 were positioned at the upper left-hand corner and quite far from the centre (origin) of the plane in the score plot, and these results were in agreement with the original collection sites which were quite distinct from each other. TZA04 and TZA08 were the two most negative along PC1 due to the lowest OTDM $(74.71 \%$ and $75.55 \%)$, OTWM $(43.34 \%$ and $44.48 \%)$, OTB $(12.41 \%$ and $12.90 \%)$, and OTF (304.06\% and 321.18\%), but highest in KTF $(14.72 \%$ and $14.55 \%)$, KTB $(9.23 \%$ and $8.93 \%)$ and KY $(12.81 \%$ and $11.68 \%)$, respectively. Despite poor performance in bunch quality components, TZA04 performed better in terms of bunch yield with the highest FFB (139.15 kg palm $\left.{ }^{-1} \mathrm{yr}^{-1}\right)$ and among the highest in $\mathrm{BNO}$ (14.41 bunches palm $\left.{ }^{-1} \mathrm{yr}^{-1}\right)$ and ABW (9.76 kg palm $\left.^{-1} \mathrm{yr}^{-1}\right)$. This outstanding performance placed TZA04 as the most positive contributors along PC2. Marhalil et al. (2009) reported that a family within population TZA04 (TZA04.06) produced the highest FFB yield $\left(148.49 \mathrm{~kg}\right.$ palm $^{-1}$ $\left.\mathrm{yr}^{-1}\right)$ and $\mathrm{BNO}\left(16.28\right.$ bunches palm $\left.\mathrm{yr}^{-1}\right)$, compared to DxP standard cross which was about $128.77 \mathrm{~kg}$ palm ${ }^{-1} \mathrm{yr}^{-1}$ and 9.09 bunches palm ${ }^{-1} \mathrm{yr}^{-1}$, respectively. Thus, it is suspected that this particular family might be the cause of the outstanding FFB of population TZA04 observed in this study.

TZA09 was the most negative along PC2 due to poor performance in some bunch yield and quality components; lowest in FFB (104.83 kg palm $\left.\mathrm{yr}^{-1}\right)$, ABW (8.47\%), BWT (9.86\%), MFW (8.51 g), MNW $(4.51 \mathrm{~g})$, OY $\left(13.76 \mathrm{~kg} \mathrm{palm}^{-1} \mathrm{yr}^{-1}\right)$ and KY $(8.42 \mathrm{~kg}$ palm $\left.{ }^{-1} \mathrm{yr}^{-1}\right)$. Other populations were positioned quite close to the centre (circled) which indicates that they have average properties of most of the variables. This is also predictable because distance among populations around the centre were not more than 20 $\mathrm{km}$ apart and might contribute to the low variability.

\section{Cluster Analysis (CA)}

Ward's method is preferred due to its efficiency and widely used for hierarchical clustering analysis (Saracli et al., 2013). In this study, three major clusters were formed in a dendrogram created on the basis of this clustering method based on Euclidean distance (Figure 3). The first cluster consisted of TZA01 and TZA13 at the bottom of the dendrogram $\left(\mathrm{L}^{2}=0.371\right)$ and the close proximity in CA reflects similarities in bunch quality traits which were also found to contribute highly to PC1 in PCA. The other branch of this cluster grouped TZA02, TZA03, TZA10, TZA05 and TZA11 together. Only one population from this cluster showed potential characteristic for high ABW (10.37 kg palm $\left.{ }^{-1} \mathrm{yr}^{-1}\right)$, which belonged to TZA10. Second cluster grouped TZA06, TZA07 and TZA12 together in a subcluster branch and TZA09 was positioned as a singleton at another branch, owing to its performance difference for half of the number of components studied. Generally, these two clusters grouped most of the populations having average value for most of the variables possibly due to low relative distance at their geographical locations.

Third cluster containing only TZA04 and TZA08 which were collected from the more southern and northern parts of Tanzania and more isolated from other populations. Even though both populations located approximately $60 \mathrm{~km}$ from each other, the same clustering $\left(\mathrm{L}^{2}=1.713\right)$ was influenced by similarities in bunch yield and bunch qualities as discussed in PCA. TZA08 and TZA04 cluster apart from the rest which shows the coherency observed between geographical position and population. It was observed that the geographical distribution patterns of these populations were not random because radial progression of the clusters seems to fit. Similar observations were also reported by LiHammed et al. (2016) who did the same analysis on MPOB-Nigeria germplasm. Marhalil et al. (2009) have suggested a family within TZA04 should be used for further breeding development and also in the formation of core collection due to its outstanding $\mathrm{BNO}$ trait.

High level of genetic variability was observed amongst the Tanzanian germplasm materials via the molecular method (Zulkifli et al., 2012) and would be beneficial if it could be exploited to broaden current oil palm genetic base. PCA and CA, combined with more advanced molecular methods, could be used to guide utilisation of MPOB-Tanzania germplasm to its fullest potential for introgression purposes and also regeneration of current germplasm for establishment of a core collection. Core collection was proposed by Frankel (1984) which interpreted as limited set of accessions in an existing collection, with minimum similarities between entries and chosen to represent genetic diversity of a large 
collection. Having core collection will reduce the maintenance efforts required against the entire germplasm. Brown (1989) suggested that core collection should be no more than $10 \%$ or practically between $5 \%$ and $20 \%$ of the collections from which they were established. Based on these parameters, the optimum number of Tanzania germplasm that should be preserved is approximately 300 to 600 palms from the whole collection. Both PCA and molecular approach in either way help to determine which populations that should be prioritised for this purpose rather than randomly select the accessions which may be redundant and not bringing any unique value to the next generation. Such systematic approach to germplasm conservation enables us to maximise genetic diversity with minimum germplasm materials for future breeding utilisation.

\section{CONCLUSION}

High variability was observed within MPOBTanzanian germplasm collection for all 15 traits used in this study. They could be introgressed with advanced breeding materials and may improve selection efficiencies upon some traits that are positively correlated, typically on FFB yield that is of high interest to most breeders. These findings, if coupled with molecular evaluation using reliable markers such as single nucleotide polymorphisms, will provide better insight of the genetic variation of Tanzania oil palm natural population, thus breeding and conservation strategies could be systematically formulated.

\section{ACKNOWLEDGEMENT}

The authors wish to express their sincere thanks to the Director-General of MPOB for permission to publish this article.

\section{REFERENCES}

Beheshtizadeh, H; Rezaie, A; Rezaie, A and Ghandi, A (2013). Principal component analysis and determination of the selection criteria in bread wheat (Triticum aestivum L.) genotypes. Int. J. Agri. and Crop Sci., 5(18): 2024-2027.

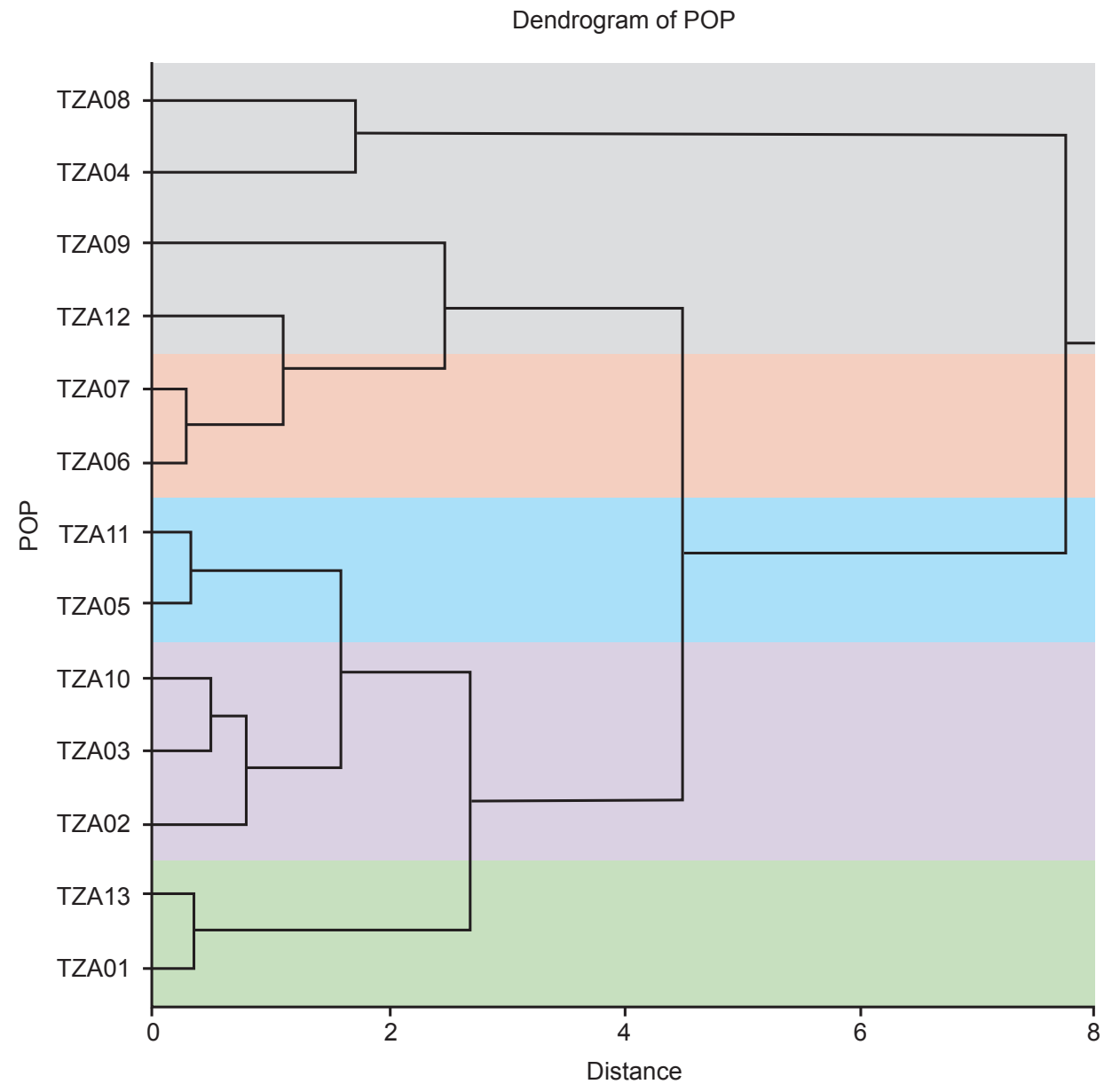

Figure 3. Dendrogram (cluster analysis tree chart) showing the relationship between 13 Tanzanian germplasm populations using 15 diverse characters. 
Beirnaert, A and Vanderweyen, R (1941). Contribution à l'étude génétique et biométrique des variétés d'Elaeis guineensis Jacquin. Publ. Inst. Nat. Etude. Agron. Congo Belge. Ser. Sci., 27: 1-101.

Blaak, G; Sparnaaij, L D and Menendez, T (1963). Breeding and inheritance in the oil palm (Elaeis guineensis Jacq.). Part II. Methods of bunch quality analysis. J. West African Institute Oil Palm Res., 4: 146155.

Brown, A H D (1989). The case for core collections. The Use of Plant Genetic Resources (Brown, A H D; Frankel, O H; Marshall, D R and Williams, J T eds.). Cambridge University Press, Cambridge, UK. p. 136156.

Camillo, J; Braga, V; De Abreu Mattos, J K; Lopes, R; Cunha, R N V; Padilha, J and Scherwinski-Pereira, J E (2014). Seed biometric parameters in oil palm accessions from a Brazilian germplasm bank. Pesq. Agropec. Bras. Brasilia, 49(8): 604-612.

Cao, D; William, D D and Williams, N E (1999). Data transformation and standardization in the multivariate analysis of river water quality. Ecological Appl., 9(2): 669-677.

Carrere, R (2013). Oil palm in Africa: Past, present and future scenarios. WRM Series on Tree Plantation No. 15. World Rainforest Movement.

Danojević, D; Ćurčić, Ž; Nagl, N; Taški-adjuković, K and Boćanski, J (2016). Evaluation of sugar beet genotypes for root traits by principal component analysis and cluster analysis. Genetika, 48(1): 339-348.

Djonko, H; Kushairi, A; Rajanaidu, N and Jalani, B S (2011). Assessment of bunch yield and its components for Cameroon-based dura x pisifera oil palm (Elaeis guineensis Jacq.) populations. Proc. of the International Society for Oil Palm Breeders (ISOPB) Seminar. MPOB, Bangi. p. 167-177.

Ekezie, D D (2013). Principal component analysis, an aid to interpretation data. A case study of oil palm (Elaeis guineensis Jacq.). J. Emerg. Trend Engine. Appl. Sci., 4(2): 237-241.

Evgenidis, G; Traka-Mavrona, E and KoutsikaSotiriou, M (2011). Principal component analysis as a tool in the assessment of tomato hybrids and cultivars. Intl. J. Agro. DOI. 10.1155/2011/697879.

Frankel, O H (1984). Genetic perspectives of germplasm conservation. Genetic Manipulation: Impact on Man and Society (Arber, W K; Llimensee, K; Peacock, W J and Starlinger, P eds.). Cambridge University Press, Cambridge, UK. p. 161-170.
Iezonni, A P and Pritts, M P (1991). Applications of principal component analysis to horticultural research. Horticultural Sci., 26: 334-338.

Isa, Z A; Ong, K P; Norasyikin, I and Suboh, O (2008). Performance of MPOB-Nigerian Population 12 at Kulim - An update. Proc. of the $3^{\text {rd }}$ Seminar on Performance of PS1 and PS2 Materials and Elite Germplasm. MPOB, Bangi. 139-149.

Jagoe, R B (1952). Deli oil palms and early introductions of Elaeis guineensis to Malaya. Malay Agri. J., 35: 4-11.

Junaidah, J; Kushairi, A; ISA, Z A; Mohd Din, A; Noh, A and Rajanaidu, N (2004). PS7: High bunch index breeding population. MPOB Information Series No. 221. MPOB, Bangi.

Khodadadi, M; Fotokian, M H and Miransari, M (2011). Genetic diversity of wheat (Triticum aestivum L.) genotypes based on cluster and principal component analysis for breeding strategies. Aust. J. Crop Sci., 5(1): 17-24.

Koij, F S and Saba, J (2015). Using cluster analysis and principal component analysis to group lines and determine important traits in white bean. Procedia Environ. Sci., 29: 38-40.

Kushairi, A (2009). Role of oil palm breeding in wealth creation and quality of life. Proc. of the $8^{\text {th }}$ Malaysia Congress on Genetics. Genting Highlands, Malaysia. p. 14-20.

Kushairi, A; Rajanaidu, N; Mohd Din, A; Isa, Z A; Noh, A and Junaidah, J (2003). PS5: Breeding populations selected for thin shell teneras. $M P O B$ Information Series No. 183. MPOB, Bangi.

Kushairi, A; Rajanaidu, N; Sundram, K and Maizura, I (2004). PS8: Vitamin E breeding population. $M P O B$ Information Series No. 222. MPOB, Bangi.

Kushairi, A; Singh, R and Ong-Abdullah, M (2017). The oil palm industry in Malaysia: Thriving with transformative technologies J. Oil Palm Res. Vol. 29(4): 431-439.

Kushairi, A; Loh, S K; Azman, I; Elina, H; Meilina, O-A; Zanal Bidin, M N R; Razmah, G; Shamala, S and Ahmad Parveez, G K (2018). Oil palm economic performance in Malaysia and R\&D progress in 2017. J. Oil Palm Res. Vol. 30(2): 163-195.

Li-Hammed, M A; Kushairi, A; Rajanaidu, N; Mohd Sukri, H; Che Wan Zanariah, C W N and Jalani, B S (2015). Multivariate analysis of vegetative and physiological traits in oil palm 
(Elaeis guineensis Jacq.) germplasm. Expert Opin. Environ. Biol., 4(3): 1-5.

Li-Hammed, M A; Kushairi, A; Rajanaidu, N; Mohd Sukri, H; Che Wan Zanariah, C W N and Jalani, B S (2016). Genetic variability for yield, yield components and fatty acid traits in oil palm (Elaeis guineensis Jacq.) germplasm using multivariate tools. Intl. J. Agri. Forest Plant, 2: 219226.

Maizura, I; Kushairi, A; Noh, A; Marhalil, M; Wong, Y T and Sambanthamurthi, R (2008). PS13: Breeding populations selected for low lipase. MPOB Information Series No. 400. MPOB, Bangi.

Maji, A T and Shaibu, A A (2012). Application of principal component analysis for rice germplasm characterization and evaluation. J. Plant Breed. Crop Sci., 4: 87-93.

Marhalil, M (2009). Performance of MPOB-Tanzania Oil Palm Germplasm Collection. MPOB 134 ${ }^{\text {th }}$ VIVA Committee Meeting. MPOB, Bangi.

Mielke, T (2018). Oil World. International Statistical Agricultural Information (ISTA) (Falk, S ed.). Mielke GmbH, Hamburg, Germany.

Mohammadi, S A and Prasanna, B M (2003). Analysis of genetic diversity in crop plants-salient statistical tools and considerations. Crop Sci., 3: 1235-1248.

Mohd Din, A; Noh, A; Mohd Isa, Z A; Maizura, I; Kushairi, A and Rajanaidu, N (2006). PS11: High carotene E. guineensis breeding population. $M P O B$ Information Series No. 312. MPOB, Bangi.

Noh, A; Rafii, M Y; Mohd Din, A; Kushairi, A; Norziha, A; Rajanaidu, N; Latif, M A and Malek, M A (2014). Variability and performance evaluation of introgressed Nigerian dura x Deli dura oil palm progenies. Genet. Mole. Res., 13(2): 24262437.

Noh, A; Rajanaidu, N; Kushairi, A; Mohd Din, A and Wan Nooraida, W M (2015). PS14: Oil palm breeding population selected for high kernel. MPOB Information Series No. 566. MPOB, Bangi.

Okwuagwu, C O and Tai, G C C (1995). Estimation of variance components and heritability of hunch yield and yield components in the oil palm (Elaeis guineensis Jacq.). Plant Breeding, 114: 463-465.

Ooi, Z X; Hanafi, I; Azhar, A B and Teoh, Y P (2014). A review on recycling ash derived from Elaeis guineensis by-product. Bioresour., 9: 7926-7940.

Rajanaidu, N (1994). PORIM Oil Palm Genebank. PORIM, Bangi. 19 pp.

Rajanaidu, N and Jalani, B S (1994). Oil palm genetic resources - collection, evaluation, utilisation and conservation. Paper presented at the PORIM Colloquium on Oil Palm Genetic Resources. PORIM, Bangi.

Rajanaidu, N; Jalani, B S; Kushairi, A and Rao, V (1992). Oil palm genetic resources: Collection, evaluation, utilisation and conservation. Proc. of the Intl. Society of Oil Palm Breeders (ISOPB). PORIM, Bangi. p. 219-255.

Rajanaidu, N; Kushairi, A and Mohd Din, A (2017). Evaluation of oil palm genetic resources. Monograph: Oil Palm Genetic Resources (Rajanaidu, $\mathrm{N}$ ed.). MPOB, Bangi. p. 93-215.

Ravishanker; Kumar, S; Baranwal, D; Chatterjee, A and Solankey, S (2013). Genetic diversity based on cluster and principal component analysis for yield and quality attributes in ginger (Zingiber officinale Roscoe). Intl. J. Plant Breed. Genet., 7(3): 159-168.

Saracli, S; Doĝan, N and Doĝan, I (2013). Comparison of hierarchical cluster analysis methods by cophenetic correlation. J. Inequalities and Applications, 203: 1-8.

Suzana, M; Zulkifli, Y; Marhalil, M; Rajanaidu, N and Mohd Din, A (2016). Principal component and cluster analysis as a tool in the assessment of genetic variability of Sierra Leone germplasm populations. Transactions of Persatuan Genetik Malaysia, 3: 213216.

Workman, D (2018). Palm oil exports by country. World's top exports (WTEx). http://www. worldstopexports.com/palm-oil-exports-bycountry/

Zulkifli, Y; Maizura, I and Rajinder, S (2012). Genetic diversity study of Elaeis guineensis germplasm using EST-SSR. J. Oil Palm Res. Vol. 24: 1368-1377. 